\title{
PROPAROXÍTONOS E ESTRATÉGIAS DE REDUÇÃO COM BASE NO CORPUS DO ALIMA*
}

\author{
PROPAROXYTONICS AND REDUCTION STRATEGIES BASED ON ALIMA'S CORPUS
}

PROPORAXÍTONAS Y ESTRATEGIAS DE REDUCCIÓN CON BASE EN EL CORPUS DEL ALIMA

\author{
Arthur Pereira Santana \\ José de Ribamar Mendes Bezerra
}

\begin{abstract}
Resumo: Análise da apócope e da síncope em proparoxítonas no falar maranhense. Investigam-se os motivadores linguísticos e extralinguísticos que condicionam o aparecimento do fenômeno na fala de 44 indivíduos (homens e mulheres), naturais de 10 municípios maranhenses, distribuídos igualmente em duas faixas etárias. Baseado teórico-metodologicamente na sociolinguística, o estudo aponta a relevância do traço de articulação da vogal, do contexto fonológico precedente e do contexto fonológico seguinte, da escolaridade e da localidade, como condicionantes do fenômeno. Assim, pôde-se concluir que o fenômeno ocorre em contextos específicos, e não gerais (ARAÚJO, 2007), bem como que os fatores extralinguísticos atuam de forma conjunta sobre o fenômeno investigado, não exercendo, portanto, influência isoladamente. Palavras-chave: Proparoxítonas. Síncope. Tonicidade.
\end{abstract}

Abstract: Study that analyzes the apocope and syncope in proparoxitones on Maranhão's speech. It searches the linguistics and extra linguistics motivators that leads to the emergence of the phenomenon on the speech of 44 individuals (men and women), born and raised in 10 different cities of Maranhão, equally distributed into two age groups. Methodologically based on the sociolinguistics theory, the paper highlights the relevancy of vowel articulation feature, precedent phonological context, following phonological context, schooling and locality as relevant towards the phenomenon appearance. Thus, it concludes that the phenomenon occurs in specific contexts, not in general (ARAÚJO, 2007), as well as the extra linguistics variables acting as a group with the other variables, not carrying out, therefore, the influence isolated.

Keywords: Proparoxitones. Syncope. Tonicity.

Resumen: Estudio que analiza la apócope y la síncope en proparoxítonas en el habla marañense. Se investiga los motivadores lingüísticos y extralingüísticos que influyen en la aparición del fenómeno en el habla de 44 individuos (hombres y mujeres), naturales de 10 municipios marañenses, distribuidos igualmente en dos grupos de edad. Basado metodológicamente en la Sociolingüística, el estudio señala la relevancia del rasgo de articulación de la vocal, del contexto fonológico precedente, del contexto fonológico siguiente, de la escolaridad y de la localidad, como condicionantes del fenómeno. Así, pudo concluirse que el fenómeno ocurre en contextos específicos, y no generales (ARAÚJO, 2007), así como los factores extralingüísticos actúan de forma conjunta sobre el fenómeno investigado, no ejerciendo, por lo tanto, influencia aisladamente.

Palabras clave: Proparoxítonas. Síncope. Tonicidad.

\section{INTRODUÇÃo}

O caráter distintivo do acento na língua portuguesa - exemplificado classicamente pelos pares sábia, sabia e sabiá - é responsável, já nos primeiros anos da vida escolar, por certa familiaridade dos falantes com noções referentes ao padrão tônico do português. Dessa forma, termos como oxítonas, paroxítonas e proparoxítonas, bem como a relação desses grupos de palavras com regras de representação gráfica do acento, são recorrentes ao longo da vida escolar do indivíduo.

Todavia, a abordagem do tema na educação básica não condiz com a complexidade enfrentada pelos pesquisadores de linguagem que têm a tônica como foco de estudo, uma vez que uma teoria geral a respeito do acento no português ainda tem algumas várias questões não solucionadas plenamente.

Autores como Câmara Jr. (1970), Bisol (1992), Wetzels (1992), Lee (1995) e Cagliari (1999) são responsáveis por análises que culminaram em três hipóteses basilares a respeito do acento no português brasileiro - a hipótese do acento livre, que considera que o acento é definido lexicalmente; a hipótese do molde trocaico, segundo a qual a estrutura silábica define o acento; e a hipótese do acento morfológico, que presume a vinculação da tônica à estrutura do vocábulo (FERREIRANETTO, 2007).

\footnotetext{
Trabalho premiado durante o XXIV Encontro do SEMIC, realizado na UFMA entre os dias 05 a 08 de novembro de 2012.

*Artigo recebido em dezembro 2012

Aprovado em fevereiro 2013
} 
Tais hipóteses, entretanto, não conseguem explicar, em sua plenitude, o comportamento dos proparoxítonos no português. A possível extrametricidade dos vocábulos cuja tônica recai na antepenúltima sílaba corrobora a ideia da "marginalidade" das proparoxítonas defendida por Câmara Jr. (1976). Essa marginalidade seria responsável por uma eminente tendência à modificação. Juntar-se-ia a isso, o fato de esse tipo de vocábulo ter entrado tardiamente no léxico do português e ter um caráter predominantemente erudito.

Araújo (2007) e Araújo et al. (2008), por sua vez, propõem uma abordagem que interpreta os processos de redução como restritos e não gerais. Assim, acreditam que as proparoxítonas, ao serem reduzidas a paroxítonas, o fazem por conta de um contexto fonológico específico favorecedor do fenômeno.

$\mathrm{O}$ interesse de pesquisadores pelo padrão tônico da língua portuguesa se dá não só por ele ser, como mencionado anteriormente, distintitivo, mas também pelo fato de a proeminência tônica dos vocábulos influenciar os padrões rítmicos, prosódicos e a articulação de certos segmentos que compõem o vocábulo.

Assim, o sistema vocálico é constituído por elementos tônicos, pré-tônicos e pós-tônicos, e o padrão articulatório destes elementos está intimamente ligado a sua posição (BISOL, 2010; CRISTÓFARO-SILVA, 2009).

Câmara Jr. (1976, apud BISOL, 2003) esquematiza o processo de neutralização das átonas no português brasileiro, doravante $\mathrm{PB}$, que levaria à redução de sete vogais na posição tônica para três na posição átona final, da seguinte forma:
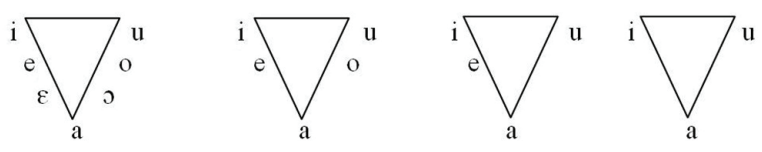

Como explicitado no esquema, enquanto a posição tônica possibilita a produção de sete vogais /i, u, e, o, $\varepsilon, o, a /$, a posição pré-tônica possibilita cinco /i, u, e, o, a/, passando a quatro, na pós-tônica não-final /i, u, e, a/, e a apenas três na pós-tônica final /i, u, a/. que:

Bisol (2003, p. 275, grifo nosso) ressalva

[...] na pauta da postônica não-final, a elevação de ambas as vogais vem ocorrendo semelhantemente ao que ocorre na átona final, embora ainda não se tenha manifestado como regra geral em nenhuma variedade do português brasileiro, diferentemente do que ocorre com a pauta final. (...) Mas a neutralização da postônica não-final, como manifestação externa da vogal alta, é uma regra variável em qualquer comunidade de fala.

Ainda que intrinsecamente relacionada com a posição da tônica, a neutralização das vogais médias não é sensível ao acento. Por sua vez, a apócope, metaplasmo caracterizado pelo apagamento de um segmento vocálico no início do vocábulo, e a síncope, caracterizada pelo apagamento do segmento vocálico no in- terior do vocábulo, têm despertado o interesse de vários pesquisadores, pois esses fenômenos, além de caracterizarem o comportamento das vogais no português, possibilitam uma reestruturação da posição da tônica no vocábulo.

Dessa forma, investigaram-se, neste artigo, os metaplasmos por supressão em vocábulos proparxítonos, uma vez que resultam na modificação da posição da tônica. Vale destacar que sua análise possibilita contribuições tanto para o desenvolvimento de uma teoria geral a respeito do acento no português, quanto uma descrição do português popular brasileiro.

\section{OS "ESDRÚXULOS" NO PORTUGUÊS}

Por serem fenômenos recorrentes na linguagem popular, a síncope e a apócope foram descritas em alguns dos primeiros estudos brasileiros em linguística sobre o português popular.

Em A língua do Nordeste, obra publicada em 1945, que tomava como base o Português falado em Alagoas e Pernambuco para suas análises, Marroquim (1996, p. 73) destaca que a síncope é um fenômeno comum devido à "dificuldade de pronunciar o proparoxítono". Para ilustrar, o autor destaca vocábulos como porva, prinspe e poliça (pólvora, príncipe e polícia, respectivamente).

Antes mesmo de Marroquim, Amadeu Amaral, em 1920, cita vocábulos como corgo e estamo (córrego e estômago), identificando-os como recorrentes em $O$ dialeto caipira, título da obra ora citada.

Por se tratar de estudos pioneiros e de caráter primordialmente descritivo, não há, nesses estudos, registros sobre a frequência de ocorrência do fenômeno na fala dos indivíduos. O mérito desses trabalhos está, portanto, no pioneirismo e no registro do Português da época. Além disso, podemos perceber que a noção de que os proparoxítonos são, de alguma forma, diferentes, se comparados aos paroxítonos, ou até mesmo estranhos ao Português, por conta de fatores como a entrada tardia no léxico do Português, começa a ser difundida tão logo a linguística no Brasil dá seus primeiros passos.

Ainda, com base na descrição feita naquele período, podemos perceber que a síncope é o principal fenômeno de caráter fonético-fonológico responsável pela suposta rejeição dos proparoxítonos.

Assim, já nos dias de hoje, Quednau, em estudo publicado em 2002, analisa a realidade das proparoxítonas fazendo um percurso desde o latim até o Português arcaico.

Segundo Quednau (2002), a síncope em proparoxítonas, apesar de extremamente estigmatizada, é um fenômeno notado desde o latim clássico e que foi intensificado na passagem para o latim vulgar. Sendo assim, a síncope de proparoxítonas é um fenômeno herdado do latim e perceptível em outras línguas como o grego clássico e o italiano. 
Para a autora, a síncope nos proparoxítonos em latim seria responsável pela não ocorrência de vocábulos de acento antepenúltimo no Português arcaico. Quednau (2002) ainda afirma que, mesmo que os autores não sejam unânimes com relação a tal constatação, apenas na segunda fase do Português arcaico, a da prosa histórica, com a latinização da cultura, é que as proparoxítonas voltam a ser incorporadas ao léxico português.

Amaral (2002) faz um levantamento dos vocábulos proparoxítonos no Português e observa que, dos 120.000 verbetes presentes no dicionário Aurélio, apenas 8.520 possuem tonicidade na antepenúltima sílaba, evidenciando o porquê de Câmara Jr., na década de 70, afirmar que os "esdrúxulos" são, no Português, "um tanto marginais" (1976, p. 35).

Além disso, a autora ainda afirma que "a síncope em proparoxítonas é previsível, ou seja, o falante tem consciência das regras fonotáticas da língua ao reduzir sílabas, apagar segmentos ou inserir outros" (QUEDNAU, 2002, p. 102).

Assim, Araújo et al. (2008) sintetizam os argumentos mais utilizados para a não inclusão das proparoxítonas em uma teoria geral a respeito do acento no Português brasileiro. São eles:

a) A baixa frequência de uso;

b) A entrada tardia no léxico do Português;

c) A extrametricalidade da vogal/sílaba final.

Todavia, os autores defendem que não há evidências suficientes que provem que o falante evita o uso de proparoxítonas e que os vocábulos proparoxítonos sempre existiram no Português, ressaltando ainda que, ao mesmo tempo em que as palavras proparoxítonas sofrem redução, há casos em que as oxítonas se transformam em paroxítonas e que as paroxítonas passam a proparoxítonas.

Baseando-se em um corpus composto de 150.875 palavras retiradas do Dicionário Houaiss, os autores ainda afirmam que determinados contextos fonológicos favoráveis ao fenômeno são os responsáveis pelos casos de redução, descartando assim a influência de fatores extralinguísticos como principais condicionantes do fenômeno.

Dessa forma, Araújo et al. (2008) buscam tratar as proparoxítonas não mais como simples exceções. Considerá-las, portanto, como estranhas, dar-se-ia pelo fato de ainda não se conseguir incluí-las em uma teoria geral a respeito do acento no $\mathrm{PB}$, e não pelo fato de elas serem externas ao Português.

É interessante observar que, apesar de a síncope ser o fenômeno mais recorrente na redução de vocábulos proparoxítonos a paroxítonos, não é o único observado na línguagem popular - a apócope também possibilita a não realização do proparoxítono pelo falante.

Chaves, em sua dissertação de mestrado sobre a redução de proparoxítonos na fala da região sul, aponta que o fenômeno pode ser notado já no latim vulgar, permanecendo no português moderno principalmente pelo apagamento do /r/ final. Entretanto, atesta, ainda, que "há uma carência de trabalhos destinados a sistematizar o processo" (CHAVES, 2011). É, pois, com o objetivo de contribuir para tal sistematização que este trabalho foi desenvolvido.

\section{METODOLOGIA}

O corpus utilizado neste estudo foi selecionado do banco de dados criado para a elaboração do Atlas Linguístico do Maranhão (ALiMA) e constituído por inquéritos realizados pelos pesquisadores do Projeto ALiMA.

Foi analisada a fala de 40 informantes, sendo 4 por município pesquisado, distribuídos por sexo e com escolaridade até a $4^{a}$ série, provenientes de 10 municípios maranhenses São Luís, Pinheiro, Turiaçu, Imperatriz, Brejo, São João dos Patos, Bacabal, Tuntum, Balsas e Alto Parnaíba - que fazem parte da rede de pontos do ALiMA e que estão indicados na figura a seguir.

Figura 1 - Municípios investigados

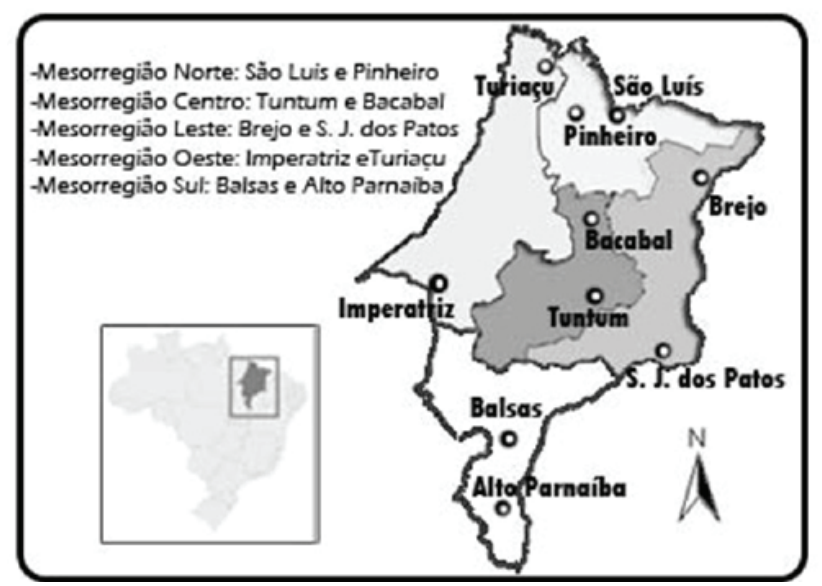

Fonte: Elaborada pelos autores

Analisamos, ainda, a fala de mais 4 informantes de São Luís, com nível superior completo, o que nos possibilitou investigar a influência da variável escolaridade na variação de proparoxítonas, no Estado, ao comparar os dados destes sujeitos com os dos outros 4 informantes de São Luís com escolaridade até a $4^{\mathrm{a}}$ série.

A análise estatística dos dados e a verificação de percentuais de ocorrência da variação das proparoxítonas foram realizadas por meio da codificação dos dados e do uso do pacote de programas VARBRUL.

Esse programa analisa as ocorrências descritas e, por meio da codificação de dados, cruza as variáveis, listando-as em ordem de relevância para o aparecimento do fenômeno, valendo-se de pesos relativos.

Foram analisados, na fala de cada informante, 26 vocábulos proparoxítonos que per- 
mitiram observar diversos contextos fonológicos e, a partir disso, analisar a maior ou menor influência de cada contexto para o aparecimento dos fenômenos investigados.

\section{A APócope}

A variação dos vocábulos proparoxítonos pode ser sensível ou não ao acento. Ou seja, nas análises depreendidas neste estudo, podemos classificar tais vocábulos de três formas distintas, levando em consideração a questão acentual: proparoxítonas, sem variação da norma culta; variante proparoxítona, vocábulos que, apesar da variação, mantêm a sílaba tônica; e variante paroxítona, resultado de um processo de redução.

Como atesta Amaral (2002), alguns contextos fonético-fonológicos favorecem o processo de redução de proparoxítonas. Em seu estudo, ao analisar o contexto fonológico seguinte dos vocábulos de sua amostragem, a autora constatou que as líquidas são as principais responsáveis pelo apagamento da vogal pós-tônica não-final, já que favorecem, no português, o surgimento de ataque complexo, como é o caso de ['avri] e ['fosfru].

Percebemos, ainda, em nossos dados, outras formas de fuga de itens proparoxítonos por meio da utilização de outros vocábulos que apresentam a mesma carga semântica que o proparoxítono, mas sem que a acentuação recaia sobre a antepenúltima sílaba (relâmpago corisco) ou, ainda, o deslocamento do acento para a sílaba seguinte (vômito > vomito).

Nossa amostra, entretanto, não possibilita que percebamos casos, como os descritos por Aragão (2000), de queda da vogal tônica (espírito > espríto), o que nos leva a crer que esse seja um fenômeno restrito a ambientes estruturais muitos particulares e, portanto, pouco recorrente na linguagem popular.

Focaremos, entretanto, nossa análise de maneira mais específica, neste tópico, na apócope de proparoxítonos. É necessário reforçar, entretanto, que analisaremos apenas os casos de apócope que resultam em uma modificação da estrutua da tônica do vocábulo. Ou seja, casos de apagamentos finais que não afetam o acento do vocábulo não serão focos de nossa análise.

Das 559 realizações analisadas, 141 apresentaram casos de redução de proparoxítonas: 120 por meio da síncope e 21 por meio de apócope, confirmando assim o favorecimento da síncope para a redução de proparoxítonas. Ainda por conta do número de recorrência de apócope na amostragem utilizada para a análise, decidimos não submeter estes dados à análise estatística do VARBRUL, uma vez que a baixa recorrência poderia resultar em resultados numéricos equivocados.

Os casos de apócope foram listados no quadro a seguir.
Quadro 1 - Visão geral da amostragem

\begin{tabular}{|c|c|c|c|c|}
\hline $\begin{array}{l}\text { REALIZA- } \\
\text { ÇÃOO }\end{array}$ & $\begin{array}{l}\text { LOCALI- } \\
\text { DADE }\end{array}$ & $\begin{array}{l}\text { ESCOLARI- } \\
\text { DADE }\end{array}$ & SEXO & $\begin{array}{l}\text { FAIXA } \\
\text { ETÁRIA }\end{array}$ \\
\hline ['gemi] & Pinheiro & $\begin{array}{l}\text { Fund. } \\
\text { Incompleto }\end{array}$ & M & II \\
\hline ['prowve] & Balsas & $\begin{array}{l}\text { Fund. } \\
\text { Incompleto }\end{array}$ & $\mathrm{F}$ & I \\
\hline ['pove] & Balsas & $\begin{array}{l}\text { Fund. } \\
\text { Incompleto }\end{array}$ & $F$ & II \\
\hline ['powve] & Balsas & $\begin{array}{l}\text { Fund. } \\
\text { Incompleto }\end{array}$ & $M$ & II \\
\hline [va'lẽmpa] & $\begin{array}{l}\text { Alto } \\
\text { Parnaíba }\end{array}$ & $\begin{array}{l}\text { Fund. } \\
\text { Incompleto }\end{array}$ & $M$ & I \\
\hline ['powve] & $\begin{array}{l}\text { Alto } \\
\text { Parnaíba }\end{array}$ & $\begin{array}{l}\text { Fund. } \\
\text { Incompleto }\end{array}$ & $F$ & II \\
\hline ['powve] & Brejo & $\begin{array}{l}\text { Fund. } \\
\text { Incompleto }\end{array}$ & $\mathrm{F}$ & II \\
\hline ['powva] & Bacabal & $\begin{array}{l}\text { Fund. } \\
\text { Incompleto }\end{array}$ & $\mathrm{F}$ & I \\
\hline ['ospi] & $\begin{array}{l}\text { S. J. dos } \\
\text { Patos }\end{array}$ & $\begin{array}{l}\text { Fund. } \\
\text { Incompleto }\end{array}$ & M & II \\
\hline ['lãpe] & Tuntum & $\begin{array}{l}\text { Fund. } \\
\text { Incompleto }\end{array}$ & M & I \\
\hline ['pove] & Tuntum & $\begin{array}{l}\text { Fund. } \\
\text { Incompleto }\end{array}$ & M & I \\
\hline ['ospi] & Tuntum & $\begin{array}{l}\text { Fund. } \\
\text { Incompleto }\end{array}$ & M & I \\
\hline ['lãpe] & Tuntum & $\begin{array}{l}\text { Fund. } \\
\text { Incompleto }\end{array}$ & $\mathrm{F}$ & II \\
\hline ['fige] & Tuntum & $\begin{array}{l}\text { Fund. } \\
\text { Incompleto }\end{array}$ & $F$ & II \\
\hline ['ospı] & Tuntum & $\begin{array}{l}\text { Fund. } \\
\text { Incompleto }\end{array}$ & $\mathrm{F}$ & II \\
\hline [E'letri] & Tuntum & $\begin{array}{l}\text { Fund. } \\
\text { Incompleto }\end{array}$ & M & II \\
\hline ['xelãpe] & Tuntum & $\begin{array}{l}\text { Fund. } \\
\text { Incompleto }\end{array}$ & $M$ & II \\
\hline ['ospi] & Turiaçu & $\begin{array}{l}\text { Fund. } \\
\text { Incompleto }\end{array}$ & $\mathrm{F}$ & I \\
\hline [E'letri] & Turiaçu & $\begin{array}{l}\text { Fund. } \\
\text { Incompleto }\end{array}$ & $M$ & I \\
\hline ['pove] & Turiaçu & $\begin{array}{l}\text { Fund. } \\
\text { Incompleto }\end{array}$ & $M$ & I \\
\hline [a'bobe] & Turiaçu & $\begin{array}{l}\text { Fund. } \\
\text { Incompleto }\end{array}$ & $M$ & I \\
\hline ['powve] & Turiaçu & $\begin{array}{l}\text { Fund. } \\
\text { Incompleto }\end{array}$ & $M$ & II \\
\hline
\end{tabular}

Fonte: Elaborada pelos autores

É possível observar, logo em uma primeira análise, que não foi registrado qualquer caso de apócope na fala de um indivíduo cuja escolaridade ultrapassa o ensino fundamental completo. Tal fato comprova a relevância do fator escolaridade para o aparecimento do fenômeno, não apenas pelo fato de a escola, na condição de agência padronizadora da língua, trabalhar no sentido de bloquear tais variações no falar do indivíduo, mas também pelas pressões sociais, uma vez que a apócope de proparoxítonas é um fenômeno bastante estigmatizado no PB, configurando-se, na maioria dos 
casos, como evidencia Bortoni-Ricardo (2004, p. 101), como "(...) um traço descontínuo, próprio do pólo rural/rurbano.". E fundamental, contudo, não perder de vista a posição defendida por Aguilera (1994) e apresentado neste estudo no tópico 5.5.

Vale relembrar que a única localidade analisada cujos informantes possuíam nível superior completo é São Luís, capital do Estado, município de caráter predominantemente urbano.

Entre os municípios que apresentaram maior número de casos de apócope estão Tuntum e Turiaçu. Localizado no Centro Maranhense, a $346 \mathrm{~km}$ de São Luís, Tuntum conta com uma população de 36.813 habitantes. O município foi criado em 1955 e tem como principal atividade econômica o comércio varejista, a agropecuária e a compra e venda de produtos de grandes indústrias do sul do país.

Turiaçu, por sua vez, dista $164 \mathrm{~km}$ de São Luís. Suas principais atividades econômicas se centram na agricultura, com o cultivo de farinha, milho, abacaxi, arroz, banana, café em grãos, laranja e feijão; na pecuária, com o cultivo de gado bovino, caprino, equino e bubalino, além de em atividades de mineração e de comércio varejista de pequeno porte e gêneros alimentícios. Turiaçu tem uma população média de 33.203 habitantes.

A baixa escolaridade dos informantes é acompanhada, nos municípios analisados, de um contexto pouco urbano que favorece, por sua vez, a manutenção na fala dos indivíduos de formas de pouco prestígio. Ressaltamos, assim, a forma como fatores sociais agem, de forma não isolada, levando a uma influência mútua.

Ainda compondo o conjunto de fatores extralinguísticos de nossa análise, os fatores sexo e faixa etária não parecem ser relevantes para o aparecimento do fenômeno, já que, quando considerados, observamos que a variação é mínima. Entretanto, vale ressaltar que uma conclusão segura a esse respeito só pode ser alcançada com a análise de um corpus mais extenso, com mais casos a serem analisados.

Com relação aos vocábulos, hóspede, apesar de não ser o mais recorrente na amostragem, é o item lexical que menos apresenta alteração, tendo como variante resultante ['ospr]. Nesse caso, há um alçamento da vogal medial /e/, seguido pelo apagamento da sílaba final.

Pólvora, por sua vez, é o vocábulo que mais sofreu apócope nos dados analisados. O apagamento da líquida vibrante e da vogal final, geralmente acompanhado de uma assmilação da pós-tônica não-final, resulta em vocábulos que apresentam, também, casos de monotongação e epêntese, como em ['pove],['prowve] e ['powve].

No estudo realizado por Chaves (2011), os fatores linguísticos que mais influenciam o aparecimento da apócope nos vocábulos realizados por falantes da região sul do País são a articulação da vogal e o contexto fonológico precedente.
Assim, são as vogais labiais que mais favorecem o aparecimento do fenômeno. Em nossos dados, o vocábulo lâmpada exemplifica casos em que uma labial possibilita a realização da apócope, como em ['lãpe].

Ainda segundo a autora, as alveolares que precedem a vogal final compõem o contexto mais favorável para o fenômeno. Em nossa amostragem é, também, esse o contexto em que a apócope pôde ser notada por mais vezes, nos casos de realização do vocábulo pólvora.

\section{A SÍNCOPE}

Para a análise da síncope de proparoxítonas em uma perspectiva sociolinguística e dialetológica, como a utilizada neste estudo, controlamos fatores linguísticos (contexto fonológico precedente, contexto fonológico seguinte, traço de articulação da vogal, peso da sílaba e extensão da palavra) e extralinguísticos (faixa etária, sexo, localidade e escolaridade).

\subsection{Traço de articulação da vogal}

O programa selecionou como fator de maior relevância para a ocorrência de síncope em proparoxítonas o traço de articulação da vogal. Sabemos, pois, que os sons vocálicos são aqueles cuja passagem de ar pelo trato vocal não sofre qualquer fricção ou interrupção (CRISTÓFARO-SILVA, 2009). Dessa forma, o que os diferencia são, no momento da articulação, a posição da língua e o arredondamento maior ou menor dos lábios.

Vogais labiais são as vogais que, para serem articuladas, necessitam de maior arredondamento dos lábios. Sendo assim, classificamos dessa forma /u/ e /o/. Sons dorsais, por sua vez, "são os sons articulados com a parte de trás do dorso da língua" (CRISTÓFARO-SILVA, 2011, p. 96). Com relação às vogais, classificamos como dorsal o /a/.

Finalmente, sons coronais são aqueles articulados com o elevamento do dorso ou da ponta da língua, acima do "ponto neutro": /e/ e /i/.

Os resultados demonstram que as vogais labiais são as que mais favorecem a síncope, como observamos na tabela a seguir.

Tabela 1 - Fator traço de articulação da vogal

\begin{tabular}{l|l|l|l}
\hline FATOR & APL. TOTAL & RECORRÊNCIA & $\begin{array}{l}\text { PESO } \\
\text { RELATIVO }\end{array}$ \\
\hline Dorsal & $12 / 134$ & $12 \%$ & 0,267 \\
\hline Coronal & $58 / 183$ & $24,1 \%$ & 0,562 \\
\hline Labial & $50 / 122$ & $29,1 \%$ & 0,624 \\
\hline
\end{tabular}

Fonte: Elaborada pelos autores

Dentre os vocábulos cuja vogal a sofrer síncope é labial, temos: fósforo, árvore, abóbora, pólvora, clavícula e rótula. Os resultados propostos pelo programa e a análise do universo de realizações tornam possível 
observar que todos os outros vocábulos, após o apagamento da vogal pós-tônica não-final, também possibilitam o surgimento de um ataque complexo, ou seja, apresentam um ambiente propício para a supressão de um segmento em seu interior.

Araujo et. Al. (2008), ao descreverem os contextos propícios ao aparecimento da síncope, afirmam que:

por definição, $[\ldots]$ o processo de síncope não ocorre quando as consoantes / $\mathrm{p} \mathrm{t} \mathrm{k} \mathrm{b} \mathrm{d} \mathrm{g} \mathrm{f} \mathrm{v} \mathrm{/} \mathrm{estiverem,}$ após a realização da síncope, nas posições de coda da tônica e onset da pós-tônica não-final. Isso se dá pelo fato de essas consoantes não serem permitidas no sistema do PB, se houvesse apagamento da vogal pós-tônica não-final, nem como coda da tônica, nem como segundo elemento de um onset complexo da pós-tônica resultante.

O vocábulo fígado, que compõe nosso corpus, ilustra tal afirmação, já que o apagamento da vogal pós-tônica /a/ impossibilitará, para os padrões do Português, a realização do vocábulo */figdo/. Tal impossibilidade, entretanto, não determina a não-variação do vocábulo. Na amostragem analisada, observamos que a estratégia usada pelo falante que busca a redução de proparoxítona é o apagamento da sílaba final - ['figa] - ou o apagamento, concomitante, da vogal pós-tônica não-final e da consoante seguinte: ['figo].

Assim, em casos em que o contexto resultante do processo de síncope é impedido pela estrutura fonotática do Português, o fenômeno não deixa de ocorrer, mas o faz paralelamente a outros fenômenos que possibilitarão, finalmente, uma estrutura aceita pelos padrões mais usuais da língua.

É válido ressaltar, entretanto, que os dados estatísticos mostram que quanto menor a sequência de fenômenos utilizados para que o contexto fonológico resultante respeite os padrões da língua, maior a probabilidade de que a variação ocorra.

Ainda sobre as vogais e os vocábulos proparoxítonos, Araujo et al. (2008) atestam que:

palavras proparoxítonas têm 2,6 vezes mais chances de terem a vogal $[\varepsilon]$ na posição acentuada e 4,4 vezes mais chances de ter a vogal [0] na posição acentuada do que palavras com acento não-proparoxítono. Isso sugere que há uma correlação entre acento e vogais médias abertas em palavras proparoxítonas (WETZELS, 1991, 1992).

$\mathrm{Na}$ amostragem desta pesquisa, pudemos perceber que na posição pós-tônica as vogais médias abertas são as mais suscetíveis à síncope. É necessária, portanto, uma análise mais profunda a respeito da relação entre vogais e o acento em proparoxítonos, já que tanto em posição tônica como em posição póstônica as médias abertas parecem exercer forte influência.

\subsection{Contexto fonológico precedente}

O segundo fator escolhido pelo programa em ordem de relevância foi o contexto fono- lógico precedente, ou seja, o ambiente que é ocupado pelos fonemas que ocorrem antes da vogal a ser apagada.

Dessa forma, a análise estatística mostrou que são as alveolares que mais favorecem o apagamento da vogal pós-tônica não-final, como pode ser visto a seguir.

Tabela 2 - Fator contexto fonológico precedente

\begin{tabular}{l|l|l|l}
\hline FATOR & APL. TOTAL & RECORRÊNCIA & $\begin{array}{l}\text { PESO } \\
\text { RELATIVO }\end{array}$ \\
\hline Labial & $40 / 203$ & $16,5 \%$ & 0,470 \\
\hline Alveolar & $39 / 63$ & $38,2 \%$ & 0,703 \\
\hline Labiodental & $31 / 82$ & $27,4 \%$ & 0,397 \\
\hline Velar & $10 / 54$ & $15,6 \%$ & 0,453 \\
\hline
\end{tabular}

Fonte: Elaborada pelos autores

Dessa forma, percebemos que são as alveolares que favorecem a formação de nova sílaba após o apagamento da vogal. Nosso universo de realizações ratifica a ideia de autores como França (2009), tendo em vista o alto número de realizações de ['kəske] observados em nossos dados.

Nesse caso, a sibilante anterior à vogal pós-tônica, após ser apagada, passa a compor uma coda bem formada, ligando-se à sílaba anterior.

Araújo (2007, p. 46) descreve realizações como essas da seguinte forma:

A sílaba pós-tônica não final é formada por uma consoante e uma vogal [i], sendo que a consoante é uma realização das consoantes contínuas coronais /s, z/. Nesse caso, a vogal pode ser apagada, ocorrendo espalhamento do traço [voz] para o onset da sílaba seguinte.

A análise do contexto fonológico seguinte, feita a seguir, nos possibilitará, assim, uma visão mais geral a respeito do contexto geral que favorece o apagamento da pós-tônica não-final.

\subsection{Contexto fonológico seguinte}

A variável contexto fonológico seguinte foi a terceira considerada mais relevante, diferentemente do que ocorre nas pesquisas de Amaral (1999) e Lima (2008), que tiveram a mesma variável como a primeira a ser escolhida.

Tendo em vista os vocábulos proparoxítonos encontrados no banco de dados do Projeto ALiMA, dividimos este fator em oclusiva, líquida lateral e líquida vibrante, como mostra a tabela que segue.

Tabela 3 - FATOR CONTEXTO FONOLÓGICO SEGUINTE

\begin{tabular}{l|l|l|l}
\hline FATOR & APL. TOTAL & RECORRÊNCIA & PESO RELATIVO \\
\hline Oclusiva & $51 / 322$ & $15,8 \%$ & 0,435 \\
\hline Líquida Lateral & $3 / 22$ & $13,6 \%$ & 0,100 \\
\hline $\begin{array}{l}\text { Líquida } \\
\text { vibrante }\end{array}$ & $66 / 215$ & $30,7 \%$ & 0,650 \\
\hline
\end{tabular}

Fonte: Elaborada pelos autores 
Fósforo, árvore, úbere, abóbora, pólvora, útero, número e elétrico, alvos de nosso estudo, são alguns dos vocábulos obtidos nas respostas dadas aos questionários aplicados pelo ALiMA. A listagem desses vocábulos nos permite evidenciar, mais uma vez, o que afirma Lima (2008, p. 92) em seu estudo:

[...] no Português brasileiro, uma estrutura silábica formada por ataque complexo terá na segunda posição do ataque uma líquida lateral /I/ ou uma líquida vibrante / $\square /$. Dessa forma, as palavras, que apresentam uma líquida na sílaba que segue a postônica, possibilitam o apagamento da vogal, favorecendo a síncope. [...] Esse resultado comprova que o apagamento da vogal postônica em palavras proparoxítonas só é permitido se, no processo de ressilabação, a consoante flutuante for incorporada à sílaba seguinte, formando uma nova estrutura silábica permitida na língua.

Tal fato, portanto, esclarece a razão pela qual /fosfro/, /arvri/ e /abobra/ são tão recorrentes na amostragem, já que conseguem acumular diversos fatores selecionados pelo programa como condicionantes para a síncope em proparoxítonas, relevando o quão propício são esses contextos para o aparecimento do fenômeno.

\subsection{Extensão da palavra}

Para Araujo et al. (2008, p. 85), "com o aumento do número de sílabas das palavras há uma tendência geral de reduzir a frequência de uso, que parece ser uma pouco mais acentuado no caso das proparoxítonas".

Buscamos examinar se a extensão da palavra exercia alguma influência no apagamento da pós-tônica não-final. Embora o programa tenha selecionado essa variável, não acreditamos que ela seja realmente atuante para a implementação do fenômeno. A tabela 4 nos ajuda a entender o motivo.

Tabela 4 - Fator extensão da palavra

\begin{tabular}{l|l|l|l}
\hline FATOR & APL. TOTAL & RECORRÊNCIA & $\begin{array}{l}\text { PESO } \\
\text { RELATIVO }\end{array}$ \\
\hline Três sílabas & $94 / 438$ & $21,5 \%$ & 0,563 \\
\hline $\begin{array}{l}\text { Mais de } \\
\text { três sílabas }\end{array}$ & $26 / 121$ & $21,5 \%$ & 0,286 \\
\hline
\end{tabular}

Fonte: Elaborado pelos autores

Como podemos observar, o peso relativo do fator trissílabo está muito próximo do ponto neutro. Além disso, o fato de possuirmos relativamente poucos casos de vocábulos polissílabos na amostragem, não nos permite afirmar com segurança que tal fator seja, verdadeiramente, relevante.

Além disso, estudos como os de Amaral (1999), Lima (2008) e França (2009) não apontam esse fator como relevante para o fenômeno da síncope. França (2009, p. 180) chega a afirmar que "isso demonstra que a síncope não é fruto decorrente diretamente do fato de as palavras estudadas terem três ou mais sílabas, ou em outras palavras, que o fator extensão não é fundamental para que o apagamento ocorra".

\subsection{Localidade}

A variável diatópica (e suas implicações de ordem social, econômica e cultural) influencia a variação linguística e pode ser considerada como um dos diversos fatores que atuam na mudança de uma língua.

Para Bortoni-Ricardo (2004), o contínuo da urbanização é responsável por várias transformações não somente na língua, mas, principalmente, na relação que os indivíduos inseridos em uma comunidade têm com a própria língua e com as variações que nela ocorrem. Sobre essa relação, a autora observa que

enquanto os falantes rurais ficavam muito isolados pelas dificuldades geográficas de acesso, como rios e montanhas, e pela falta de meios de comunicação, as comunidades urbanas sofriam a influência de agências padronizadoras da língua, como a imprensa, as obras literárias e, principalmente, a escola. (BORTONI-RICARDO, 2004, p. 52).

Dessa forma, os dados desta pesquisa levaram o VARBRUL a selecionar a variável localidade como relevante para a ocorrência da síncope, destacando-se nesse contexto os municípios de Tuntum, Pinheiro e São João dos Patos como as localidades que apresentaram o maior número de realizações do fenômeno.

Tabela 5 - Fator localidade

\begin{tabular}{c|c|c|c}
\hline FATOR & $\begin{array}{c}\text { APL. } \\
\text { TOTAL }\end{array}$ & RECORRÊNCIA & $\begin{array}{c}\text { PESO } \\
\text { RELATIVO }\end{array}$ \\
\hline Pinheiro & $16 / 58$ & $27,6 \%$ & 0,631 \\
\hline Balsas & $16 / 58$ & $27,6 \%$ & 0,591 \\
\hline Alto Parnaíba & $10 / 55$ & $18,2 \%$ & 0,457 \\
\hline Brejo & $7 / 57$ & $12,3 \%$ & 0,346 \\
\hline Bacabal & $12 / 55$ & $21,8 \%$ & 0,550 \\
\hline Imperatriz & $13 / 59$ & $22 \%$ & 0,503 \\
\hline S. J. dos Patos & $15 / 51$ & $29,4 \%$ & 0,630 \\
\hline Tuntum & $17 / 56$ & $30,4 \%$ & 0,644 \\
\hline Turiaçu & $11 / 56$ & $19,6 \%$ & 0,495 \\
\hline São Luís & $3 / 54$ & $5,6 \%$ & 0,192 \\
\hline Fonte: Elaborad
\end{tabular}

Fonte: Elaborada pelos autores

Como todos os informantes analisados para o estudo da influência do fator geográfico possuem o mesmo nível de escolaridade, ensino fundamental incompleto variando somente a localidade, percebemos que em São Luís o contato com as variantes de maior prestígio, além de influenciar no falar dos indivíduos, torna as formas não-padrão ainda mais estigmatizadas, forçando os falantes não somente a se policiarem, mas também a almejarem a condição de usuários da variante culta.

Sobre o fato de o processo de redução de proparoxítonas no Português ser característico 
apenas do falar rural, Aguilera (1994, p. 812) afirma que as variantes proparoxítonas:

[...] não apresentam uma correlação entre uma forma específica e sua distribuição diatópica. Este fato corrobora a hipótese de que o fator geográfico não é determinante da frequência de uso de proparoxítonas ou paroxítonas.

Tal hipótese ainda é reforçada pelo fato de esse processo ser percebido no Brasil em sua totalidade, tanto em áreas rurais como urbanas. O programa, por exemplo, apontou a segunda maior cidade do Estado - Imperatriz - como relevante para a ocorrência de síncope.

Essa realidade levou à investigação mais profunda do caso do município, já que os traços de urbanidade, aparentemente, ainda não produziram efeitos na língua. Percebemos, assim, que os resultados do Indice de Desenvolvimento da Educação Básica (IDEB) evidenciam que o município não avançou no que diz respeito ao desenvolvimento educacional: em 2005, 2007 e 2009, o município obteve o índice de 3,6, inferior, por exemplo, ao do município de Balsas, que ocupa a terceira posição no ranking dos municípios maranhenses, tendo como parâmetro o PIB .

Tal fato possibilita observar de maneira mais clara como as variáveis linguísticas e extralinguísticas não operam de modo autônomo, e sim exercendo influência umas sobre as outras constantemente, já que é impossível analisar a questão da localidade, por exemplo, sem levar em consideração a variável escolaridade, enfocada no tópico seguinte.

\subsection{Escolaridade}

Como apontado anteriormente, para que pudéssemos analisar a influência da variável escolaridade na realização do fenômeno, foi necessário utilizar inquéritos realizados com informantes que possuem curso superior completo.

Dessa forma, as rodadas com os dados de que dispúnhamos de informantes do município de São Luís, dos dois níveis de escolaridade, e que foram previamente descritos, apresentou como resultado um nocaute.

Em outras palavras, o programa evidenciou que, entre os informantes de São Luís com nível superior completo, não houve qualquer caso de síncope da vogal pós-tônica não-final em proparoxítonas, ou seja, não houve variação, daí o nocaute.

Isso leva a concluir, portanto, que a variável escolaridade é relevante para a ocorrência do fenômeno, já que indivíduos com maior escolaridade, como mostram os dados, tendem a não reduzir as proparoxítonas. Por outro lado, os informantes de São Luís, com nível de escolaridade fundamental incompleto, apresentaram casos de síncope, ainda que em número reduzido, por conta das pressões de agências padronizadoras e da influência do fluxo de urbanização presente na capital.
Fica clara, portanto, a influência da escolaridade nos processos de variação de proparoxítonas. O mesmo resultado é encontrado por Aguilera (1994) e Castro (2001), em suas respectivas pesquisas sobre o falar paranaense, $\mathrm{e}$ por Aragão (2000) sobre o falar de Fortaleza. Aguilera (1994, p. 818) afirma ainda que,

Dos fatores extralinguísticos testados, o grau de escolaridade tem uma ampla influência na escolha entre realizações proparoxítonas e paroxítonas, comprovado pela preferência de $62 \%$ dos escolarizados por formas proparoxítonas e $64 \%$ dos não escolarizados pelas paroxítonas.

É interessante observar que, além da clara influência da escolaridade dos indivíduos na redução ou variação de proparoxítonas, ela exerce forte influência sobre outros motivadores sociolinguísticos.

\section{CONSIDERAÇÕES FINAIS}

Araújo et al. (2007) e Araújo (2008) propõem uma nova abordagem para os vocábulos de acento antepenúltimo com o objetivo de incluí-los nas teorias gerais a respeito do acento no Português. Essas teorias, como visto anteriormente, tentavam explicar a redução ou variação de proparoxítonas alegando a suposta entrada tardia de vocábulos dessa natureza, no léxico, sua baixa frequência de uso $\mathrm{e}$, consequentemente, a iminente tendência à modificação.

Nos dados utilizados nesta pesquisa, pudemos observar que, assim como defendem Araújo et al. (2007) e Araújo (2008), é o contexto fonológico o grande responsável pelo aparecimento de fenômenos que mudam o padrão acentual dos proparoxítonos. Como mais um argumento favorável à tese que defendem, os autores evidenciam que o número de casos de manutenção da tônica é superior aos casos de redução, por meio de estratégias diversas. Essa constatação leva-os a se posicionarem contra a ideia de que as proparoxítonas obedecem a uma modificação.

Sendo assim, observamos que a síncope é mais propensa a aparecer quando o apagamento da pós-tônica não-final resulta em um ataque complexo ou em uma coda bem formada. Percebemos ainda que, quando o contexto não se mostra favorável, é possível que a síncope ocorra paralelamente com outros metaplasmos que resultem em um contexto final possível e não estranho ao Português, ainda que com menos frequência, se comparados a quando o ambiente é favorável à implementação do fenômeno.

Com relação aos fatores externos, ressaltase a relevância, principalmente, da variável escolaridade que, como observamos, é responsável pela consciência que o indivíduo passa a ter de que o uso de formas padrão, de modo geral, será responsável por maior respaldo social.

Os dados não permitem analisar questões como a data de entrada do vocábulo no léxico 
do Português, um dos argumentos apresentados para a não inclusão dos vocábulos de acento antepenúltimo nas teorias a respeito do acento na língua. Entretanto, pretendemos, em trabalhos futuros, analisar a questão da frequência de uso de vocábulos proparoxítonos na fala dos indivíduos de nossa amostragem.

Sobre a apócope, os fatores internos observados apontam a relevância, como já foi atestado em outros estudos, do traço de aritculação da vogal e do contexto fonológico precedente para ocorrência do fenômeno.

É necessário, ainda, que análises mais pontuais a respeito de questões como o apagamento da tônica em proparoxítonos, a flutuação de acento em proparoxítonos no diminutivo e a relação entre acento/síncope e vogais labiais sejam feitas.

\section{REFERÊNCIAS}

AGUILERA, Vanderci. As proparoxítonas na linguagem popular e rural paranaense. In: ENCONTRO NACIONAL DA ANPOLL, 9., 1994, Caxambu. Anais... João Pessoa: ANPOLL, 1994. v. 2, p. 808-818.

AMARAL, A. O dialeto caipira: gramática, vocabulário. 4.ed. São Paulo: HUCITEC/INL, 1982.

AMARAL, Marisa Porto do. As proparoxítonas: teoria e variação. 1999. 222f. Tese

(Doutorado em Letras) - Faculdade de Letras, Pontifícia Universidade Católica do Rio Grande do Sul, Porto Alegre, 1999.

A síncope em proparoxítonas:

uma regra variável. In: BISOL, Leda; BRESCANCINI, Cláudia. (Org.). Fonologia e variação: recortes do português brasileiro. Porto Alegre: EDIPUCRS, 2002, p. 99-126.

ARAUJO, Gabriel Antunes de. A proparoxítona e o sistema acentual do português. In: . (Org.). O acento em português.São Paulo: Parábola Editorial, 2007.

ARAUJO, Gabriel Antunes et al. Algumas observações sobre as proparoxítonas e o sistema acentual do português. Cadernos de Estudos Lingüísticos, Campinas, v. 50, p. 6990, 2008.

ARAGÃO, Maria do Socorro Silva de. As palavras proparoxítonas no falar de fortaleza. In: Acta Semiotica et Linguistica. São Paulo, v. 8, p. $61-88,2000$.

BISOL, Leda (Org.). Introdução a estudos de fonologia do português brasileiro. Porto Alegre: EDIPUCRS, 1996.

A neutralização das átonas. Revista Letras (Curitiba), Curitiba - Paraná, v. 61, p. 273-283, 2003

O acento e o pé métrico binário. CEL 22, 1992. p. 69-80.
BORTONI-RICARDO, Stella Maris. Educação em língua materna: a sociolinguística na sala de aula. São Paulo: Parábola Editorial. 2004.

CAGLIARI, Luiz Carlos. Acento em português. Campinas: Edição do autor, 1999.

. Elementos de fonética do português

brasileiro. São Paulo: Paulistana, 2007.

CÂMARA JR., Joaquim Matoso. Estrutura da língua portuguesa. Petrópolis: Vozes, 1970.

História e estrutura da língua

portuguesa. Rio de Janeiro: Padrão, 1976.

CASTRO, M. C. D.; AGUIAR, M. S. O alçamento e abaixamento vocálicos no dialeto da região dos gerais de Balsas. Signótica, v. 19, p. 277-298, 2007.

CASTRO, Vandersi Sant'Ana. A redução de proparoxítonas no português popular do Brasil: estudo com base em dados do Atlas Linguístico do Paraná (ALPR). Estudos Linguísticos, São Paulo, v. 1, 2001. Disponível em: <http://www.gel. org.br/estudoslinguisticos/volumes/37/EL V37N2_12.pdf>. Acesso em: 14 out. 2010.

CHAVES, Raquel Gomes. A redução de proparoxítonos na fala do sul do Brasil. 2011. 173 f. Dissertação (Mestrado em Letras) - Programa de Pós-Graduação em Letras, Pontifícia Universidade Católica do Rio Grande do Sul, Porto Alegre, 2011.

CRISTÓFARO-SILVA, Thaïs. Fonética e fonologia do português: roteiro de estudos e guia de exercícios. 9. ed. São Paulo: Contexto, 2009.

. Dicionário de fonética e fonologia. São Paulo: Contexto, 2011.

FERREIRA NETTO, Waldemar. O acento na língua portuguesa. In: ARAUJO, Gabriel Antunes de (Org.). O acento em português. São Paulo: Parábola Editorial, 2007.

FRANÇA, Sebastião Adauto. O apagamento da vogal postônica não-final por falantes de Jaru - Estado de Rondonia. Acta Scientiarum, Language and Cultura. v. 31, n. 2, p. 169 182, 2009. Disponível em: <http://periodicos. uem.br/ojs/index.php/ActaSciLangCult/ article/view/6202>. Acesso em 8 mar. 2011.

LEE, Seung-Hwa. Morfologia e fonologia lexical do português do Brasil. 1995. Tese (Doutorado em Linguística) - Instituto de Estudos da Linguagem, Universidade Estadual de Campinas, Campinas, 1995.

O acento primário no português:

uma análise unificada na teoria da otimalidade. In: ARAUJO, Gabriel Antunes de (Org.). O acento em português. São Paulo: Parábola Editorial, 2007.

LIMA, Giselly de Oliveira. O efeito da síncope nas proparoxítonas: análise fonológica e variacionista com dados do sudoeste goiano. 
2008. 216 f. Dissertação (Mestrado em Linguística) - Programa de Pós-Graduação em Linguística, Universidade Federal de Uberlândia, Uberlância, 2008.

MARROQUIM, Mário A. A língua do nordeste: Alagoas e Pernambuco. Curitiba: HD livros, 1996.

QUEDNAU, Laura Rosane. A evolução do latim clássico para o latim vulgar. Signum, v. 17, n. 1, p. 123-147, 2004.
. A síncope e seus efeitos em latim e português arcaico. In: BISOL, Leda; BRESCANCINI, Cláudia. (Org.). Fonologia e variação: recortes do português brasileiro. Porto Alegre: EDIPUCRS, 2002. p. 99-126.

WETZELS, Leo W. Mid-vowel neutralization in Brazilian Portuguese. CEL 23, p. 19-55, 1992. Primary word stress in Brazilian Portuguese and the weight parameter. In: Journal of Portuguese Linguistics, n. 6, p. 9-58, 1991. 